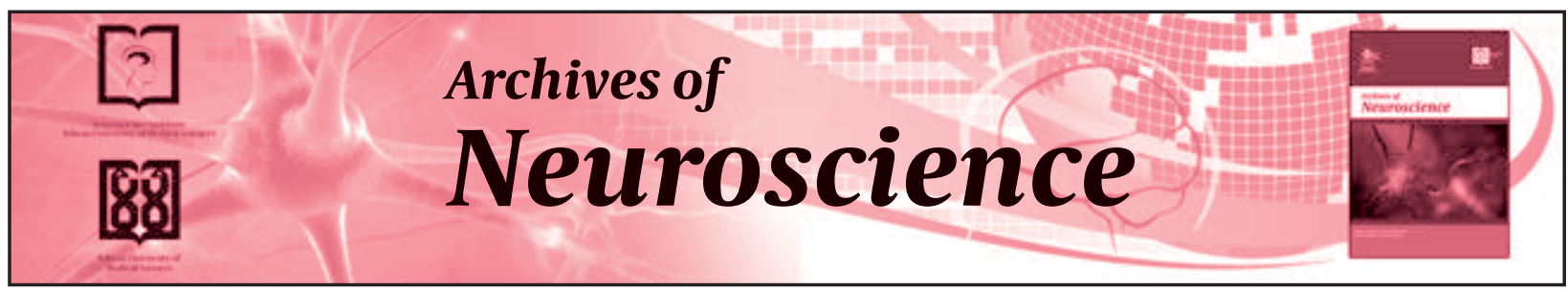

\title{
Transpedicular Screw Insertion Guidance Device (TSIGD), A New Device for Spinal Transpedicular Screw Placement (A Pilot Study)
}

\author{
Mostafa Torkashvand ${ }^{1}$, Mehran Moradi ${ }^{2,}$, , Saeid Abrishamkar ${ }^{1}$, Majid Rezvani ${ }^{1}$, Masih \\ Sabouri ${ }^{1}$, Mojtaba Miri ${ }^{2}$, Salman Abbasi Fard ${ }^{1}$ \\ ${ }^{1}$ Department of Neurosurgery, Al Zahra Hospital, Isfahan University of Medical Sciences, Isfahan, Iran \\ 2 Department of Neurosurgery, Emam Khomeini Hospital, Tehran University of Medical Sciences, Tehran, Iran \\ ${ }^{*}$ Corresponding author: Mehran Moradi, Department of Neurosurgery, Emam Khomeini Hospital, Tehran University of Medical Sciences, Tehran, Iran. Tel: \\ +98-9126850514, Fax: +98-2188088856, E-mail: drmoradim@gmail.com.
}

\begin{abstract}
A B S T R A C T
Background: Trans-pedicular screw placements have been an increasingly popular procedure in many neurosurgery and orthopedic departments. Any mistake at performing the technique could be followed by irreversible neurological deficit and damage of Para spinal vital structures as well as less stability for future fusion.

Objectives: In this study we tried to show the benefits and capabilities of a new device, Transpedicular Screw Insertion Guidance Device (TSIGD) for best possible correct transpedicular screw placement.

Patients and Methods: This study is a quasi-experimental study performed in 2010 in Isfahan at Al-Zahra General hospital. The study was based on the application of a new device, which is named Transpedicular Screw Insertion Guidance Device (TSIGD) that leads the neurosurgeon to find the Proper Pedicular Angle (PPA).

Results: 10 patients were enrolled in this study, all of them with the waiver of consent. A total of 54 screws were assigned to evaluate the capability of the TSIGD for correct screw placement by PPA(Proper Pedicular angle) and SA (Screw Angle). Only 2 screws (5.5\%) were identified as medial pedicular breach on postoperative CT scans without any neurological deficit. The mean Proper Pedicular Angle (PPA) was 26.15 ( \pm 0.4 ) that was calculated based on axial CT scan performed before the operation and mean screw angel(SA) that was calculated based on axial CT scan after the operation was $25.79( \pm 0.8),(\mathrm{P} \geq 0.05)$.

Conclusions: Not only this method is less expensive for the patients but it also saves time during surgery in contrast to CT based surgery. Also, this device is useful for neurosurgical assistants and young surgeons to reduce misplacement of pedicular screw.
\end{abstract}

Keywords: Insertion; Device; Pilot Projects

Copyright @ Tehran University of Medical Sciences.

\footnotetext{
Article type: Research Article; Received: 04 Mar 2013; Revised: 07 Apr 2013; Accepted: 16 Apr 2013; Epub: 01 Apr 2014 ; Ppub: 20 Apr 2014 Implication for health policy/practice/research/medical education:

This project evaluated the effectiveness of the Transpedicular Screw Insertion Guidance Device (TSIGD) for proper insertion of the pedicular screws . To our knowledge, it is the first project in this manner.
}

Please cite this paper as:

Torkashvand M, Moradi M, Abrishamkar S, Rezvani M, Sabouri M, Miri M, et al. Transpedicular Screw Insertion Guidance Device (TSIGD), A New Device for Spinal Transpedicular Screw Placement (A Pilot Study). Arch Neurosci. 2014; 1(1): 26-30. DOI: 10.5812/arhcneurosci.11057

Copyright (c) Tehran University of Medical Sciences.

This is an Open Access article distributed under the terms of the Creative Commons Attribution License (http://creativecommons.org/licenses/by/3.0), which permits unrestricted use, distribution, and reproduction in any medium, provided the original work is properly cited. 


\section{Background}

Transpedicular screw placements have been increasingly popular procedures and in the past decade they have been the center of attention in many neurosurgery and orthopedic departments, all over the world for the treatment of different spinal disorders including deformity, degenerative spine disease, trauma, and tumors (1-4). Earlier fixation devices involved the use of hooks and wires instead of pedicle screw-assisted instrumentation, but because the application of transpedicular system is almost always more rigid and includes the fusion and stabilization of three columns of the spine they had been replaced by other devices. Meanwhile this technique needs more experiences and accessibility $(2,3,5)$.

An understanding of pedicle screw insertion techniques as well as the quality of bone, pedicle dimension and the complications that may occur is necessary with this method of spine fixation. For many experienced surgeons the placement of the screw is still a great challenge. The safety and accuracy of the technique are important; view and different ways have been tried to find the best way of screw insertion (6-8). Any mistake at performing the technique could be followed by irreversible neurological deficit and damage of Para spinal vital structures as well as less stability for future fusion $(9,10)$. For increasing safety and reducing complications that may occur with the free-hand technique of Trans-Pedicular Screw Placement (TPSP) different ways have been reported including application of C-arm X-ray view, application of axial computed tomography scan (CTS), frameless stereotactically guided screw placement and different guidance devices (1-6). However, the application of all these devices and techniques are not so easy and even in many operating rooms such kinds of instruments are not available.

For correct placement of pedicular screw there are many variables such as; anatomical variation of the shape and morphology of vertebra and pedicle, the curvature of the spine which change during positioning of the patient during the surgical procedure, as well as biomechanical point of view of instruments such as screw design details and biomechanics of instruments (7-11).

\section{Objectives}

In this study we tried to show the benefits and capabilities of a new device, Transpedicular Screw Insertion Guidance Device (TSIGD) for best possible correct transpedicular screw placement. Screw Insertion Guidance Device (TSIGD), was designed by $\mathrm{M}$. Torkashvand for the best possible precise transpedicular screw placement.

\section{Patients and Methods}

This study is a quasi-experimental study performed during 2010 at Isfahan University of medical sciences in
Al-Zahra General hospital. The study was based on the application of a new device, which was designed by M. Torkashvand and was named as Transpedicular Screw Insertion Guidance Device (TSIGD) that leads the neurosurgeon to find the proper pedicular angle (PPA). Overall 54 screws were inserted in 10 patients by TSIGD. Six patients were suffering from spondylolisthesis (20 screws) and four (34 screws) were operated because of traumatic spine fractures. Screws were inserted from S1 up to T7.

Multi slice CT scan was performed for each patient before the operation. The Proper Pedicular Angle (PPA) was calculated for each vertebra on transpedicular axial view of the CT scan that was selected for placement of pedicular screw. PPA and Entry Point (EP) were respectively defined as the angle between the line that passes through the midline of the pedicle and the line that passes exactly through the midline, anterior-posteriorly of the vertebral body and the EP which is the junction of the transverse process and the superior facet of interested vertebra. The cephalic-caudal angle (CCA) for pedicle of each vertebra is calculated on sagittal CT reconstruction views. CCA is an angle between two lines, one that passes through the midline of each pedicle and the other is parallel to the horizon. Hereby EP, CCA and PPA, which are necessary for correct screw placement, are available. Transpedicular Screw Insertion Guidance Device (TSIGD) is used to place the anticipated trajectory of the screw (Figures 1 and 2).

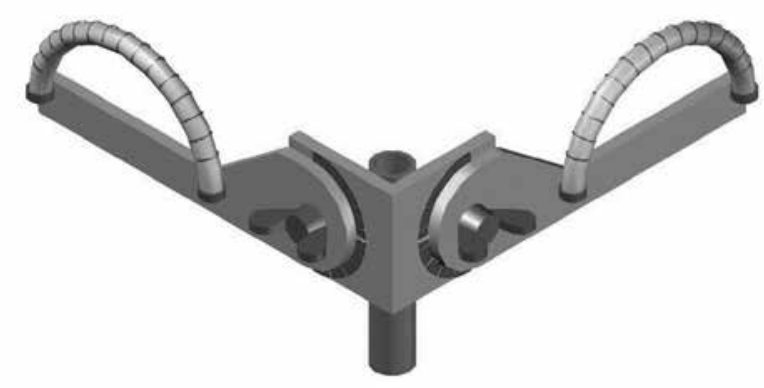

Figure 1. Transpedicular Screw Insertion Guidance Device

This device consists of two narrow semi-circle tube protractors that are perpendicularly connected to each other. The junction of the two protractors has a narrow channel, which had been designed for the passage of awl or screwdriver. Each tube is filled up by a colored fluid with a small air bubble inside. The bubble of air could easily move through the tube and because of the effect of gravity it always has an upside position. On each protractor the scale from 0 to 90 degrees had been marked so that by bending the complex of the protractor an awl neurosurgeon could see the cephalic-caudal angle (CCA) aswell as the medial-lateral angle, that is PPA, simply by displacement TSIGD and therefore the bubble 
of air inside the protractors.

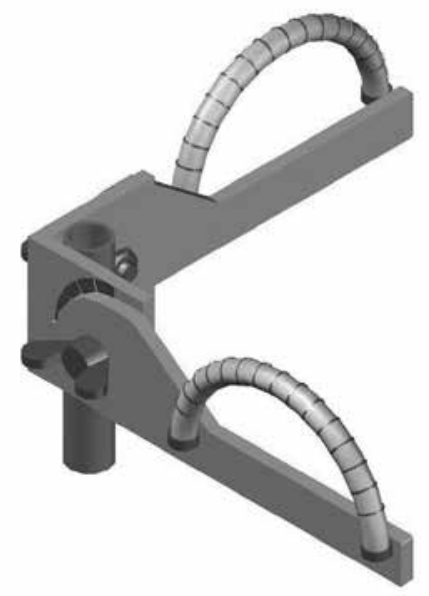

Figure 2. Transpedicular Screw Insertion Guidance Device

At the time of screw placement, the PPA and CCA that had been already calculated before the operation, were used for correct placement of the pedicular screw. For this purpose the tip of the awl will be placed on EP and by changing the direction of the TSIGD the bubble of air approach is used to calculate PPA and CCA and then the surgeon makes the trajectory hole for screw placement.

After the operation when the patients are discharged to the ward, a CT scan is performed and on the axial view, the Screw Angle (SA) is calculated. SA is defined by the angle between the lines that pass through the screw axis and the one that pass exactly through the midline anteriorposteriorly of the same vertebral body.

Statistical analysis: Descriptive statistics, including proportions, means and standard deviations, were compiled for all demographic data.

Finally to evaluate the capability of TSIGD for correct screw placement CCA and SA of each level was compared by paired t-test. $\mathrm{P}<0.05$ was considered statistically significant. SPSS 11.0 software package (SPSS Inc., Chicago IL, USA) was used for statistical analyses.

\section{Results}

Ten patients were enrolled in this study and all with the waiver of consent. A total of 54 screws were assigned to evaluate the capability of TSIGD for correct screw placement by PPA (Proper Pedicular angle) and SA (Screw Angle). Overall, mean age ( \pm standard deviation) in this study group was $40.3( \pm 0.7)$ years. Four patients $(40 \%)$ were female and six patients (60\%) were male. 20 screws (37\%) were applied in spondylolisthesis and 34 screws (63\%) were applied in traumatic spine fractures. Sixteen screws $(29.6 \%)$ were placed in thoracic vertebrae and 38 screws $(70.4 \%)$ were placed in lumbosacral vertebrae.
Only 2 screws were identified as medial pedicular breach on postoperative CT scan without any neurological deficit.

The mean Proper Pedicular Angle (PPA) was 26.15 ( \pm 0.4 ) that was calculated based on axial CT scan performed before the operation and mean screw angel (SA) that was calculated based on the axial CT scan after the operation was 25.79 ( \pm 0.8 ). There was no statistically significant difference between PPA and SA (paired t-test, P $\geq 0.05$ ) (Table 1).

\begin{tabular}{|c|c|c|c|c|}
\hline Level & $\begin{array}{l}\text { Number of } \\
\text { Screws (Left } \\
\text { and Right) }\end{array}$ & $\begin{array}{l}\text { Mean Pre- } \\
\text { operative } \\
\text { Angle }\end{array}$ & $\begin{array}{l}\text { Mean Post- } \\
\text { operative } \\
\text { Angle }\end{array}$ & Pvalue \\
\hline T7 & 4 & 19.75 & 19.25 & 0.7 \\
\hline T8 & 2 & 20 & 20 & 1 \\
\hline T9 & 2 & 24 & 23.5 & 0.4 \\
\hline T10 & 2 & 20 & 20 & 1 \\
\hline T11 & 6 & 22.17 & 22.34 & 0.6 \\
\hline T12 & 8 & 23.17 & 22.17 & 0.08 \\
\hline L1 & 2 & 27.5 & 27.5 & 1 \\
\hline L2 & 6 & 26.34 & 25.67 & 0.2 \\
\hline L3 & 8 & 29.375 & 29.5 & 0.3 \\
\hline L4 & 8 & 33.75 & 30.62 & 0.07 \\
\hline L5 & 2 & 31 & 31.5 & 0.6 \\
\hline S1 & 4 & 36.75 & 37.5 & 0.5 \\
\hline
\end{tabular}

Mean angle difference between PPA and SA in thoracic vertebrae was $0.50( \pm 0.3)$ and for lumbosacral vertebrae was 0.57 ( \pm 0.2 ) (paired t-test, $P \geq 0.05)$. Mean angle difference between PPA and SA in traumatic spine fracture was $1.1( \pm 0.3)$ but for spondylolisthesis it was $1.23( \pm 0.2)$ (paired t-test, $\mathrm{P} \geq 0.05$ ).

\section{Discussion}

Pedicle screws fixation have considerably enhanced the results of spinal surgery and spinal fusion during the two recent decades and now it is the treatment of choice for surgical intervention such as spine neoplastic lesion, developmental, congenital, traumatic, and degenerative conditions. Although it is a safe and effective way for spine fixation but still its complications are not minor to be ignored $(1,2)$.

Although a correct technique could provide a straightforward, direct, and easy method to very safely apply pedicle screws placement (TPSP) in any region of the spine but serious or frequent complications may occur (5). Training in TPSP should be considered in neurosurgical training programs since this technique represents the best way of spine fixation but this depends on the facility of the department in which this technique is being practiced. 
For the first time Roy et al. recommended that a TPSP should be introduced by making the path and then applying the screw. But very soon many surgeons realized the dangers of this technique. Thus many neurosurgeons decided to apply a blunt technique and use biplane imaging during TPSP. Since then the use of taping pedicle and biplane x-ray imaging to place the screw correctly have been widely accepted. Application of sophisticated techniques and instruments such as the CT scan, navigation, EMG and different devices have had more of less beneficial effects $(10,11)$.

Like any kind of surgical intervention complications had been reported by TPSP. The most common problems were screw misplacements that had been reported to range from $10 \%$ to $22 \%$ in scoliosis spine surgery and up to $4.2 \%$ in those with degenerative diseases. The second most common complication is Dural injury which has been reported in 7 out of 124 patients and in 2 out of 89 patients in two different series of TPSP for the treatment of degenerative spine disease. In contrast, in our study only 2 screws (5.6\%) were identified as medial pedicular breach on postoperative CT scan but in this situation no neurological deficits were detected $(5,6)$.

Nerve-root or cauda equina injury has been reported to be associated with radicular leg pain as well and sensory deficit, and sometimes this has been reported in up to $11.5 \%$ of cases (1). Because the blunt technique is superior to drilling methods in many centers now this is the preferred way of TPSP.

Two main complications related to TPSP including nerve root injury and thecal sac injury almost always occur because of screw misplacement. Although application of different methods could reduce the probability of complication but these techniques are sometimes very expensive or potentially dangerous and sometimes not accessible for routine application. Navigation techniques that had been developed and suggested for clinical application could improve correct TPSP but this is an expensive method and time consuming technique with its potential dangers $(7,8)$.

Free hand technique and X-ray by C-arm method for application of TPSP are especially more popular in departments that lack sophisticated instruments. Screw misplacement, thecal sac and nerve root injuries are still more frequent in such situations. Here the surgeons do not have any idea about the three dimensions of the spine and are only restricted to a general imagination of the pedicular angle and the trajectory for correct PSP (5). So according to all these pitfalls and problems we decided to apply the TSIGD for the best possible TPSP. Also Eftekhar et al. (12) introduced surgical simulation software for insertion of pedicle screws. It seems that TSIGD in combination with this software could be useful for preoperative and postoperative management.

\section{Conclusions}

Not only this method is less expensive for the patients but also it saves time during surgery, in contrast to CT based surgery. In addition this device is useful for neurosurgical assistants and young surgeons so as to reduce misplacement of pedicular screw.

\section{Acknowledgements}

The authors gratefully acknowledge the nurses and residents of al Zahra hospital.

\section{Authors' Contribution}

Torkashvand participated in the trail and device design. Torkashvand, Moradi and Abbasi fard were involved in the study analysis and summary. Moradi and Torkashvand obtained data. Moradi, Sabouri, Rezvani and Miri participated in the data analysis and interpretation of the results. All authors reviewed the final version.

\section{Financial Disclosure}

None declared.

\section{Funding/Support}

None declared.

\section{References}

1. Modi HN, Suh SW, Fernandez H, Yang JH, Song HR. Accuracy and safety of pedicle screw placement in neuromuscular scoliosis with free-hand technique. Eur Spine J. 2008;17(12):1686-96

2. Sakamoto T, Neo M, Nakamura T. Transpedicular screw placement evaluated by axial computed tomography of the cervical pedicle. Spine (Phila Pa 1976). 2004;29(22):2510-4

3. Braun V, Rath SA, Antoniadis G, Richter HP. In vivo experiences with frameless stereotactically guided screw placement in the spine--results from 75 consecutive cases. Neurosurg Rev. 2001;24(2-3):74-9

4. Jang JS, Lee WB, Yuan HA. Use of a guide device to place pedicle screws in the thoracic spine: a cadaveric study. Technical note. $J$ Neurosurg. 2001;94(2 Suppl):328-33

5. Ludwig SC, Kramer DL, Balderston RA, Vaccaro AR, Foley KF, Albert TJ. Placement of pedicle screws in the human cadaveric cervical spine: comparative accuracy of three techniques. Spine (Phila Pa 1976). 2000;25(13):1655-67

6. Nolte LP, Zamorano LJ, Jiang Z, Wang Q, Langlotz F, Berlemann U. Image-guided insertion of transpedicular screws. A laboratory set-up. Spine (Phila Pa 1976). 1995;20(4):497-500

7. Reinhold M, Magerl F, Rieger M, Blauth M. Cervical pedicle screw placement: feasibility and accuracy of two new insertion techniques based on morphometric data. Eur Spine J. 2007;16(1):47-56

8. Soyuncu Y, Yildirim FB, Sekban H, Ozdemir H, Akyildiz F, Sindel $M$. Anatomic evaluation and relationship between the lumbar pedicle and adjacent neural structures: an anatomic study. $J$ Spinal Disord Tech. 2005;18(3):243-6

9. Howington JU, Kruse JJ, Awasthi D. Surgical anatomy of the C-2 pedicle. J Neurosurg. 2001;95(1 Suppl):88-92

10. Xu R, Ebraheim NA, Ou Y, Yeasting RA. Anatomic considerations of pedicle screw placement in the thoracic spine. Roy-Camille technique versus open-lamina technique. Spine (Phila Pa 1976). 
1998;23(9):1065-8

11. Krag MH, Weaver DL, Beynnon BD, Haugh LD. Morphometry of the thoracic and lumbar spine related to transpedicular screw placement for surgical spinal fixation. Spine (Phila Pa 1976).
1988;13(1):27-32

12. Eftekhar B, Ghodsi M, Ketabchi E, Rasaee S. Surgical simulation software for insertion of pedicle screws. Neurosurgery. 2002;50(1):222-3| 